\title{
A CELEBRAÇÃO DA CHAVE DA ACADEMIA ou FESTA SYMBOLICA DA ATTENÇÃO
}

Conferencia do Dr. JOÃO MENDES DE ALMEIDA JUNIOR, director da Faculdade, na festa academica do encerramento dos periodos lectivos do anno escolar.

Meus caros snrs. estudantes,

A attenção é a chave das operações da mente, porque quem não attende não apprehende idéas, não forma juizos, não forma nem coordena raciocinios. A attenção é o trabalho da intelligencia, é o esforço constitutivo do estudo; quem não attende não estuda e, por isso, quem não attende não entende.

Aos professores compete o trabalho de attender para ensinar; mas, aos estudantes tambem compete o trabalho de attender para aprender. Quem não attende tem o espirito fechado e só a attenção póde abril.o. A chave da Academia não é, portanto, sómente aquella que se acha em poder do porteiro do edificio da Faculdade; a chave da Academia se acha principalmente em poder dos estudantes, visto que só póde consistir na attenção que elles prestem á doutrina professada nas aulas.

Ensinar é excitar a intelligencia do discipulo, para que este, por sua operação propria, aprenda, julgue e raciocine. Aprender é apprehender e comprehender; e, para que os senhores apprehendam e comprehendam, hão de attender e manter a attenção; ora, a attenção é um esforço da mente e, portanto, um trabalho pessoal. 
A intelligencia não funcciona sem as operações da mente, das quaes a principal é a attenção. O sublime Chrysippo, a columna do Portico, affirma que a tensão do meio psychico, pela qual se effectua o pensamento, é comparavel á tensão do meio aereo, pela qual o sensivel se transmitte aos sentidos. Eu não pretendo verificar a extensão desta analogia:- para os estoicos, a representação age como um choque sobre o espirito, que é o sôpro quente emittido pela razão; mas, seja comó fôr, a tensão desse meio psychico, para que possa vibrar ao choque das idéas que as palavras exprimem, exige uma funcção activa, funç̧ão que se revela na attenção.

Cicero, em um bellissimo trecho das Tusculanas, nota que - para entender, é preciso attender: isto é, torna-se preciso que tambem o espirito, o proprio espirito, veja e ouça, e não que sómente os olhos e os ouvidos vejam e ouçam. Os olhos e os ouvidos, diz elle, nada mais são do que janellas da alma, as quaes não serão aproveitadas pela intelligencia, mesmo que recebam as sensações, si a mente não estiver ali presente e agindo.

A attenção é, portanto, a presença e a acção da intelligencia; suppre (mesmo acceita a explicação dos estoicos), além da sensação, a comprehensão e o assentimento. A sensação provem da excitação dos orgams dos sentidos, produzindo o jogo dos nervos centripetas e centrifugos, segundo ensinam os physiologistas; a comprehensão já suppõe formada a imagem, uma elaboração dos centros nervosos, provocando o esforço intellectual para distinguir as notas que constituem a idéa; o assentimento, que completa a percepção, já requer maior energia na tensão da potencia intellectual, exigindo a intervenção de um appetite racional. 
Muitas vezes a actividade da mente se enfraquece ou desvia-se a tal ponto, que os sentidos não conseguem-levar as suas impressões até os centros nervosos: é o que se chama distracção.

Isto vem provar que, propriamente no corpo, não ha sentido algum: o corpo tem apenas os orgams (musculos e nervos); mas, da alma é que sae a vitalidade desses orgams, afim de que lhe transmittam impressões que se transformem em especies sensiveis, das quaes o intellecto possa abstrahir as especies intelligiveis, para apprehender e comprehender as essencias das cousas.

A sensação não attinge senão os singulares e o corporeo; o intellecto, porém, conhece a essencia da cousa, despojada de suas qualidades sensiveis, e, por isso, o seu objecto formal é immaterial e universal. Os senhores reflictam e verão que, para chegarem ao conhecimento das cousas, por suas notas essenciaes, que consistem nas differenças genericas e nas differenças especificas, e não nas differenças puramente individuaes, - não lhes basta a potencia passiva dos orgams dos sentidos:- para conhecer as essencias das cousas, os senhores precisam de uma potencia activa, de uma força, de um esforço, que torne comprehensivel a razão por que a cousa é o que é. Este esforço se manifesta pela attenção.

Tão importante é• a attenção, que Maine de Biran chega a confundil-a com a vontade, a ponto de fazer consistir na attenção o exercicio da liberdade e do livre arbitrio. 'A attenção, diz Maine de Biran, não é senão a mesma vontade no exercicio caracteristico da percepção, caracter que ella não mantem emquanto se acha sob as leis exclusivas da sensibilidade; o livre arbitrio nada mais é do que o poder que possue a alma de dar força aos motivos a que attende. Ora, a attenção é um esforço; o sentimento do esforço é 
o facto primitivo da consciencia; acompanha toda a acção, constitue o fundo do nosso eu. Pela attenção é que nós somos uma força, uma força consciente de si mesma, uma força que se possue a si. mesma, vis sui conscia, vis sui potens. Em summa, diz elle, só o homem que attende, póde ser dono de si proprio, porque sabe criar o esforço constitutivo do eu'.

O grande instrumento do pensamento, diz o sabio jesuita Bonniot, é a attenção, isto é, o poder que tem a intelligencia de fixar-se, de concentrar-se sobre um objecto, e de examinar-lhe os differentes aspectos. Emquanto a attenção não intervem, accrescenta elle,as sensações e as imagens podem se succeder, mas ficam inefficazes para o pensamento.

Por isso, eu quero que os senhores não sómente sintam, mas tambem attendam ás minhas palavras. A palavra, emquanto vocabulo, é um simples conjuncto de sons articulados; mas, eu não quero que os senhores apenas ouçam o vocabulo, quero que tambem attendam, isto é: apprehendam e comprehendam a idéa que o vocabulo exprime, afim de que o vocabulo se torne palavra. Eu não quero mesmo que os senhores sejam simples ouvintes da minha palavra; quero que sejam tão factores da minha palavra como eu : --factores verbi et non auditores tantum, como dizia São Thiago Apostolo. A multiplicação da sciencia tem como factores tanto quem ensina como quem aprende: sem dois factores não ha multiplicação possivel.

A didactica nada mais é do que a disposição de meios para despertar e manter a attenção dos estudantes: o anno escolar, os periodos lectivos; a dis. tribuição das materias e ordem dos cursos; a localisação, horario e frequencia das aulas; o methodo das prelecções e das lições; a policia disciplinar: - tudo isto tem por fim estabelecer o estado de consistencia no espirito, 
para que os estudantes tendam a apprehender as idéas que o professor thes communica em conferencias, quer deduzindo os preceitos ou leis dos principios geraes, quer induzindo dos exemplos ou casos particulares os costumes que se traduzem nos mesmos preceitos ou leis.

Propriamente fallando, diz Santo Agostinho, um homem ensina a outro homem, tornando-o attento ás idéas que elle já tem e das quaes decorrem as novas idéas que the são despertadas. Toda a doutrina e toda a sciencia, diz Aristoteles, vem de um conhecimento preexistente. Quem ensina, diz Santo Themaz de Aquino, ou forma proposiçбes geraes, que o estudante póde comprehender e apreciar com auxilio dos principios primarios universaes que já tem no espirito: ou mesmo, quando emprega exemplos sensiveis, semelhanças, contrarios, ou outros meios analogos, fortifica o entendimento do estudante, fazendo-lhe sentir a relação entre as consequencias e os principios geraes que elle já conhece; porque ha em todo o homem uma intelligencia dos primeiros principios, que são os principios geraes de todas as sciencias.

O ensino é a communicação de idéas pela transmissão dos respectivos signaes, que são os termos ou palavras: signum in, signare in, assignalar no espi. rito do discipulo as idéas que elle tem obscuras, como quem indica um objecto sensivel a um homem que não o vê, mostrando-o com o dedo, fazendo-lhe voltar os olhos para elle e distinguil-o com a vista. Ora, correlativamente a esta distinç̧ão das cousas sensiveis pela vista, que é o sentido fiscalizador de todos os outros, ha a distincção das cousas intelligiveis pela attenção, que é o acto inicial e fiscalizador de todas as outras operações da mente. As idéas se definem pelo genero proximo e pela differença especifica e, por isso, segundo affirmou Aristoteles,-entender é distinguir; 
a distincção pela intelligencia consiste na determinação da differença especifica e é feita pela attenção ás idéas que as palavras exprimem.

O ouvido é o sensus disciplina, exactamente porque a palavra é um som animado, exprimindo uma idéa. Mesmo admittindo que os sons das palavras sejam mecanicamente impressos no cerebro, estes sons são o signal de idéas, juizos, raciocinios, de sorte que quem os ouve não sente sómente, mas tambem pensa e reflecte. Quer isto dizer que a intelligencia não é um simples recipiente de percepções derivadas dos sentidos do corpo; é tambem, e principalmente, uma força activa.

O conhecimento é uma funç̧ão vital, pela qual o sujeito cognoscente recebe e exprime em si mesmo a acção e a forma da cousa; assim se verifica que o conhecimento consta de tres elementos, isto é, de um sujeito cognoscente, de um objecto cognoscivel, e do acto da união entre este e aquelle, de sorte que, formal. mente, o conhecimento consiste neste acto de união pelo qual o objecto é apprehendido pelo sujeito ¿ neste representado por meio da especie expressa.

Esta especie, que é a forma da cousa sensivel, está de um modo na cousa material, de outro modo na alma, porque na cousa está segundo o seu ser material e na alma está segundo o seu ser representativo. Assim, a acção da luz, até mesmo a imageın que se pinta nos olhos, é material, como ensina a experiencia; mas, emquanto se impõe ao sentido, vae se tornando immaterial e se di\% especie sensivel. Quando, porém, por virtude do intellecto agente, a especie é despida de toda a propriedade ou condição individual, a especie é então inteiramente immaterial, e costuma chamar-se-especie intelligivel. 
O intellecto tem uma dupla virtude: é abstractivo, em quanto torna intelligivel em acto a essencia ou forma das cousas sensiveis; é perceptivo, emquanto apprehende as cousas intelligiveis. $\mathrm{O}$ intellecto tem uma força abstrativa pela qual do conhecimento individual chegamos ao conhecimento geral, por exemplo, da percepção de Pedro chegamos á noção de homem. $\mathrm{O}$ intellecto tem tambem uma força ou potencia pela qual, recebendo as cousas intelligiveis, concebe a idéa; mas, esta percepção intellectiva não é uma méra paixão ou passividade do intellecto, porém uma operação que o mesmo exerce, uma vez recebida a determinação, operação pela qual o intellecto exprime em si mesmo o verbo ou idéa, pela qual percebe a cousa e. exprime a essencia.

Alguns chamam a esta força intellectual perceptiva -intellecto possivel ou intellecto paciente, em correlação á força abstractiva, que denominam - intellecto agente; mas, a verdade é que a força perceptiva, comquanto primariamente passiva e movida por seu objecto, torna-se activa para apprehender e conhecer. $\mathrm{O}$ intellecto agente illumina e abstrahe, de sorte que é causa efficiente da intelligibilidade; o intellecto possivel apprehende e conhece, de sorte que é causa efficiente da intellecção, pela qual é aperfeiçoado o conceito, a idéa, o verbo da mente. Isto revela que a actividade intellectual se manifesta tanto no intellecto agente como no intellecto possivel; a acçāo abstractiva do intellecto agente e a acção receptiva do intellecto possivel se fazem ao mesmo tempo, isto é, concorrem para a producção do mesmo acto intel. lectual e, portanto, são causas necessariamente simultaneas.

$O$ intellecto tem funç̧ões, isto é, causas finaes especificas de sua actividade, que são - apprehender, julgar, raciocinar; e tem operaçőes, isto é, actos de 
exercicio de sua actividade, que são a attenção, a abstracção, a reflexão, a analyse, a synthese e a comparaçâo, as quaes todas se reduzem á attenção.

A attenção é o acto pelo qual a mente tende a exercer-se, applicando-se a apprehender alguma cousa; a abstracção é uma especie de attenção, pela qual de duas cousas por sua natureza conjunctas, cogitamos de uma sem outra; a reflexâo é a attenção da mente aos proprios actos; a analyse é a abstracção applicada ás idéas; a synthese é a composição dé muitas idéas em um só conceito, suppondo assim a comparação, que é a attenção dirigidá ás relações entre duas ou mais cousas ou idéas, ou entre dois ou mais juizos. A attenção, em summa, é um estado de consistencia no espirito, como diz Bossuet, necessario para apprehender, julgar, raciocinar e coordenar raciocinios; pela attenção temos o espirito sempre aberto, assim como pela distracção temos o espirito fechado. Os inglezes, referindo-se á attenção que o Juiz deve prestar aos autos e ans debates, empregam a phrasekeep his mind open-manter seu espirito aberto.

Os estudantes, para que possam comprehender e aproveitar o ensino, precisam attender, isto é, precisam manter o espirito aberto. A attenção é, portanto, a chave das operações da mente; quem não attende não entende. Esta chave pertence aos estudantes; esta festa symbolica é, por conseguinte, a festa da attenção.

A transmissão desta chave, com a constituição do respectivo deposito, é a festa symbolica da attenção: os estudantes, que sahem formados, despertam nos estudantes, que ficam, a consciencia do dever de corresponder aos intuitos do Estado, quando creou, instituiu e constituiu uma fundação nacional, da qual os estudantes são os destinatarios; as gerações academicas se succedem, affirmando solemnemente a perpe- 
tuidade de uma fundação, que é, além de tudo, um compromisso constitucional e que, portanto, não póde ser desofficialisada, emquanto houver estudantes que frequentem as aulas.

Finalmente, esta chave deu entrada e sahida ás nossas geraçð̃es de magistrados, advogados, e homens politicos, desde I 827 até hoje, entre os quaes muitos brilharam e brilham, como estrellas de primeira grandeza, não só na jurisprudencia, como na legislatura, no governo e na administração. 